\title{
Global Initiative for Chronic Obstructive Lung Disease (GOLD) Revisions 2001-2017: Historical and Critical Perspective
}

Claus F. Vogelmeier, MD, FERS'1, Gerard J. Criner, MD, FACP, FACCP², and Fernando J. Martinez, MD, MS ${ }^{3}$

${ }^{1}$ Department of Medicine, Pulmonary and Critical Care Medicine, University Medical Centre Giessen and Marburg, Philipps-Universität Marburg, Member of the German Centre for Lung Research (DZL), Marburg, Germany; ${ }^{2}$ Lewwis Katz School of Medicine at Temple University, Philadelphia, Pennsylvania, USA; ${ }^{3}$ Division of Pulmonary and Critical Care Medicine, Weill Cornell Medicine, New York, USA

\section{ABSTRACT}

In 2001, the first Global Initiative for Chronic Obstructive Lung Disease (GOLD) document was published with the goal to improve the diagnosis, prevention and treatment of chronic obstructive pulmonary disease (COPD). Since then, three major revisions (GOLD 2007, 2011 and 2017) have been released. In this review, we describe the basic principles of the first document and how it has evolved over time. Initially, assessment was based exclusively on the level of airflow limitation. Nowadays, airflow limitation, respiratory symptom load and exacerbation history are taken into account. Bronchodilators have always been first-line. However, the indication for inhaled corticosteroids (ICS) has evolved over time. Non-pharmacological therapies are now considered to be of equal importance. In the latest version, interventional methods, palliative care, and end-of-life strategies have been added. The prevention and adequate treatment of exacerbations are highlighted and an expanded discussion of comorbidities has been added. (BRN Rev. 2017;3:151-65) Corresponding author: Claus F. Vogelmeier, Claus.Vogelmeier@med.uni-marburg.de

Key words: Assessment. Chronic obstructive pulmonary disease (COPD). Definition. Prevention. Treatment. 


\section{INTRODUCTION}

It all started with a scientific symposium in 1958, that resulted in a paper published in Thorax in $1959^{1}$. In this manuscript, the groundwork was laid for the years to come. The participating British investigators agreed on definitions and terminology. Interestingly, at that time, the recommendation was to summarize the terms chronic bronchitis, asthma and emphysema under "chronic non-specific lung diseases". The authors concluded that this term should be avoided and, instead, the individual's situation should be described, e.g. if a patient had chronic bronchitis, asthma and irreversible obstructive lung disease, they proposed "chronic bronchitis with partially reversible obstructive lung disease (with or without emphysema)".

The term chronic obstructive pulmonary disease (COPD) was introduced in the 60's in the United States ${ }^{2-4}$. Over the following decades, COPD became an increasing health problem with an enormous impact regarding morbidity, mortality and costs worldwide, but many experts felt that the disease did not receive adequate attention. Against this background, the National Heart, Lung, and Blood Institute (NHLBI) and the World Health Organization (WHO), under the leadership of Suzanne Hurd, Claude Lenfant and Nikolai Khaltaev, endorsed the formation of the Global Initiative for Chronic Obstructive Lung Disease (GOLD), a group of committed scientists chaired by Romain Pauwels. The main objectives of GOLD were to increase awareness for COPD and improve the diagnosis, treatment and prevention of the disease ${ }^{5}$.

In this article, we review the most relevant aspects of the initial GOLD document and the most important changes that were implemented in the three major revisions since then.

\section{GOLD 2001}

The first GOLD report was published in $2001^{6}$. Even in this first manuscript, the authors assessed the referenced literature by the level of evidence.

\section{Definition}

The authors presented a definition of COPD with the following characteristics: not fully reversible and usually progressive airflow limitation, abnormal inflammatory response of the lungs and induction by noxious particles or gases.

\section{Risk factors}

The most relevant risk factor for COPD was stated to be exposure to cigarette smoke. Additionally, other exposures that may predispose individuals to develop COPD were mentioned, including biomass fuels, occupational hazards and childhood respiratory infections.

\section{Diagnosis and assessment}

The presence of a post-bronchodilator forced expiratory volume in one second $\left(\mathrm{FEV}_{1}\right)<80 \%$ of the predicted value in combination with an $\mathrm{FEV}_{1}$ /forced vital capacity (FVC) $<70 \%$ was used as the threshold for a significant, not fully reversible, airflow limitation. The authors suggested that a diagnosis of COPD should be 
"considered in any patient presenting symptoms of cough, sputum production, or dyspnoea, and/or a history of exposure to risk factors for the disease". The presence of airflow limitation confirms the diagnosis. Where "spirometry is unavailable, the diagnosis of COPD should be made using all available tools". For "educational reasons", the authors proposed a four-stage classification system of disease severity that was exclusively based on the level of airflow limitation: stage 0 : at risk - normal spirometry $\left(\mathrm{FEV}_{1} / \mathrm{FVC} \geq 70 \%\right)$ in the presence of chronic bronchitis; stage I: mild COPD $-\mathrm{FEV}_{1}$ $>80 \%$ predicted; stage II: moderate COPD $30 \%<\mathrm{FEV}_{1}<80 \%$ predicted (IIA: $50 \%<\mathrm{FEV}_{1}$ $<80 \%$ predicted, IIB: $30 \%<\mathrm{FEV}_{1}<50 \%$ predicted); stage III: severe COPD - $\mathrm{FEV}_{1}<30 \%$ predicted, or the presence of respiratory failure, or clinical signs of right heart failure.

Spirometry was considered more relevant than symptoms and individuals with symptoms, but normal spirometry was a feature of the at-risk group for developing COPD with subsequent development of airflow limitation. The paper does not provide the basis on which the staging system is based. Interestingly, the system as suggested by the American Thoracic Society (ATS) ${ }^{7}$, British Thoracic Society (BTS) ${ }^{8}$ and European Respiratory Society (ERS) ${ }^{9}$ also included stages defined as mild, moderate and severe, but the level of airflow limitation that defined the stages varied from each other and from the GOLD report.

\section{Prevention and treatment}

Reduction of risk factors with the focus on smoking cessation was emphasized. The recommended treatments (Table 1) were stage-dependent with the following concepts: a) bronchodilators came first; combining agents with different mechanisms and durations of action might increase the degree of bronchodilation for equivalent or lesser side effects; b) inhaled corticosteroids (ICS) can be given in patients suffering from "significant symptoms" and a "significant lung function response" (IIA, III) and/or "if repeated exacerbations (IIB, III) are present"; c) nonpharmacological treatments such as vaccination and rehabilitation were given a prominent role. The recommendations regarding ICS were based on several trials ${ }^{10-13}$. It was suggested to complete a trial of six weeks to three months with ICS (a so-called ICS test) to identify COPD patients who may benefit from longterm inhaled glucocorticosteroid therapy.

\section{Exacerbations}

A considerable part of the manuscript was devoted to exacerbations, without offering a definition. The principles of exacerbation treatment were highlighted: bronchodilators, systemic steroids, antibiotics in cases with clinical signs of infection, and non-invasive ventilation, all of which remain as valid treatment interventions. However, one exception to this was theophylline; at that time theophylline was still recommended as treatment of acute exacerbations, which is not the case any longer.

\section{GOLD 2007}

\section{Definition}

The definition ${ }^{14}$ was revised by mentioning that "some significant extra-pulmonary effects 
TABLE 1. Global Initiative for Chronic Obstructive Lung Disease (GOLD) 2001. Therapy at each stage of disease

\begin{tabular}{|c|c|c|c|}
\hline Stage & Characteristics & \multicolumn{2}{|c|}{ Recommended treatment } \\
\hline All & & \multicolumn{2}{|l|}{$\begin{array}{l}\text { Avoidance of risk factors } \\
\text { Influenza vaccination }\end{array}$} \\
\hline $0:$ At risk & $\begin{array}{l}\text { Chronic symptoms (cough, sputum) } \\
\text { Exposure to risk factors } \\
\text { Normal spirometry }\end{array}$ & & \\
\hline I: Mild COPD & $\begin{array}{l}\mathrm{FEV}_{1} / \mathrm{FVC}<70 \% \\
\mathrm{FEV}_{1} \geq 80 \% \text { predicted } \\
\text { With or without symptoms }\end{array}$ & \multicolumn{2}{|c|}{ Short-acting bronchodilator when needed } \\
\hline II: Moderate COPD & $\begin{array}{l}\text { IIA } \\
\mathrm{FEV}_{1} / \mathrm{FVC}<70 \% \\
50 \% \leq \mathrm{FEV}_{1}<80 \% \text { predicted } \\
\text { With or without symptoms } \\
\text { IIB } \\
\mathrm{FEV}_{1} / \mathrm{FVC}<70 \% \\
30 \% \leq \mathrm{FEV}_{1}>50 \% \text { predicted } \\
\text { With or without symptoms }\end{array}$ & $\begin{array}{l}\text { Regular treatment with one or more } \\
\text { bronchodilators } \\
\text { Rehabilitation } \\
\text { Regular treatment with one or more } \\
\text { bronchodilators } \\
\text { Rehabilitation }\end{array}$ & $\begin{array}{l}\text { Inhaled glucocorticosteroids if significant } \\
\text { symptoms and lung function response } \\
\text { Inhaled glucocorticosteroids if significant } \\
\text { symptoms and lung function response } \\
\text { or if repeated exacerbations }\end{array}$ \\
\hline III: Severe COPD & $\begin{array}{l}\mathrm{FEV}_{1} / \mathrm{FVC}<70 \% \\
\mathrm{FEV}_{1}>30 \% \text { predicted or presence } \\
\text { of respiratory failure or right } \\
\text { heart failure }\end{array}$ & \multicolumn{2}{|c|}{$\begin{array}{l}\text { Regular treatment with one or more bronchodilators } \\
\text { Inhaled glucocorticosteroids if significant symptoms and lung function response } \\
\text { or if repeated exacerbations } \\
\text { Treatment of complications } \\
\text { Rehabilitation } \\
\text { Long-term oxygen therapy if respiratory failure } \\
\text { Consider surgical treatments }\end{array}$} \\
\hline
\end{tabular}

Reproduced with permission from GOLD.

COPD: chronic obstructive pulmonary disease. FEV $_{1}$ : forced expiratory volume in one second. FVC: forced vital capacity.

.... may contribute to the severity" or, in other words, "comorbidities" were introduced. Besides, it was stated that the disease is "preventable and treatable". This was meant to emphasize the importance of measures for prevention and to counter therapeutic nihilism.

\section{Diagnosis and assessment}

The classification of severity was still based exclusively on spirometry. But in this edition, the following stages were proposed: stage I - mild; stage II - moderate; stage III - severe; stage IV - very severe. The former IIA became stage II; the former IIB stage III; the former III stage IV. Stage 0 was no longer included, as there "is incomplete evidence that the individuals who meet the definition of 'at risk' (chronic cough and sputum production, normal spirometry) necessarily progress on to stage I". This was based on findings from the Copenhagen City Heart Study ${ }^{15}$. The analysis showed that GOLD 0 did not identify subsequent airways obstruction and was not a stable feature, which may explain the lack of predictive value.

\section{Prevention and treatment}

The table focusing on therapy from GOLD 2001 was replaced by a graph (Fig. 1) that proposed a stage-dependent step-up of treatments. 


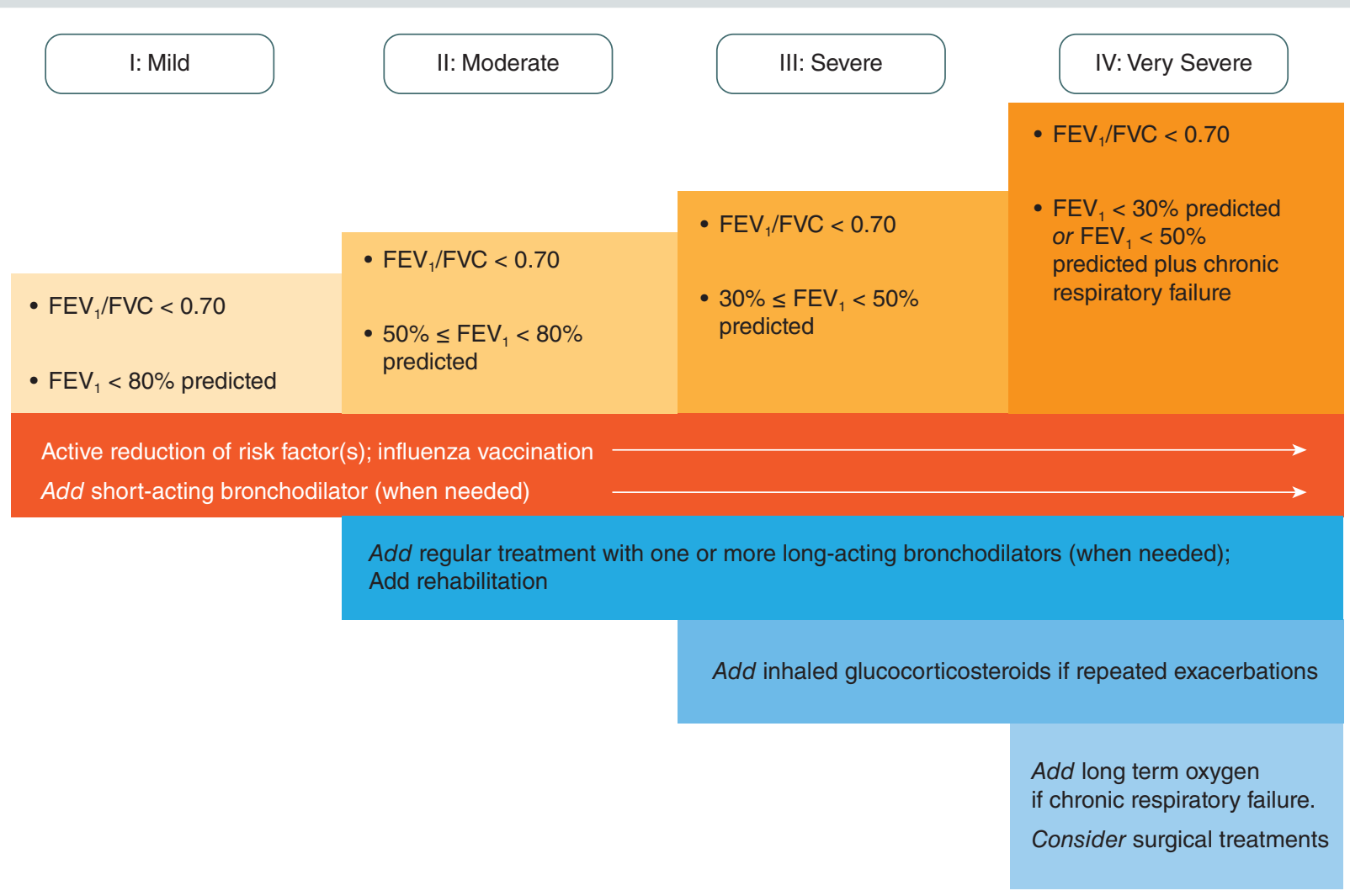

Figure 1. Global Initiative for Chronic Obstructive Lung Disease (GOLD) 2007. Therapy at each stage of disease (reproduced with permission from GOLD).

$\mathrm{FEV}_{1}$ : forced expiratory volume in one second; FVC: forced vital capacity.

There was only one relevant change concerning the use of drugs: ICS were now recommended if $\mathrm{FEV}_{1}$ is $<50 \%$ predicted and the patient suffers from "repeated exacerbations". This recommendation was based on re-analyses of older trials ${ }^{16}$ and new trials that had been performed with fixed dose long-acting $\beta_{2}$-agonist (LABA) -ICS combinations $^{17-19}$. Based on these findings, it was stated in GOLD 2007 that the combination is "more effective than the individual components".
The ICS test that was part of the 2001 recommendations was no longer mentioned.

Importantly, the authors state that long-term treatment with oral glucocorticoids was not recommended.

\section{Dissemination}

The authors state that "there is considerable evidence that management of COPD is generally 
not in accordance with current guidelines. Better dissemination of guidelines and their effective implementation in a variety of health care settings are urgently required". Based on this, the concept of "GOLD National Leaders" was introduced.

\section{GOLD 2011}

The executive summary of GOLD 2011 was published in $2013^{20}$.

\section{Diagnosis and assessment}

Spirometry was now required to make a confident diagnosis. The new assessment system was not exclusively focused on spirometry. Instead, patients were categorized into groups $\mathrm{A}$ to $\mathrm{D}$ based on the assessment of symptoms and risk of exacerbations as defined by $\mathrm{FEV}_{1}$ and exacerbation history (whichever was worse).

It was proposed to quantify symptoms by using questionnaires such as the COPD assessment test (CAT) ${ }^{21,22}$ or scales like the modified Medical Research Council (mMRC) dyspnoea scale ${ }^{23}$. Results from the Evaluation of COPD Longitudinally to Identify Predictive Surrogate End-points (ECLIPSE) study ${ }^{24}$ suggested that a history of previous treated events is a good predictor of having frequent exacerbations (two or more exacerbations per year). Besides, GOLD 4 patients had a higher exacerbation rate per year than GOLD 3 and GOLD 2 patients. Therefore, both parameters were used for prediction of exacerbation risk (Fig. 2)

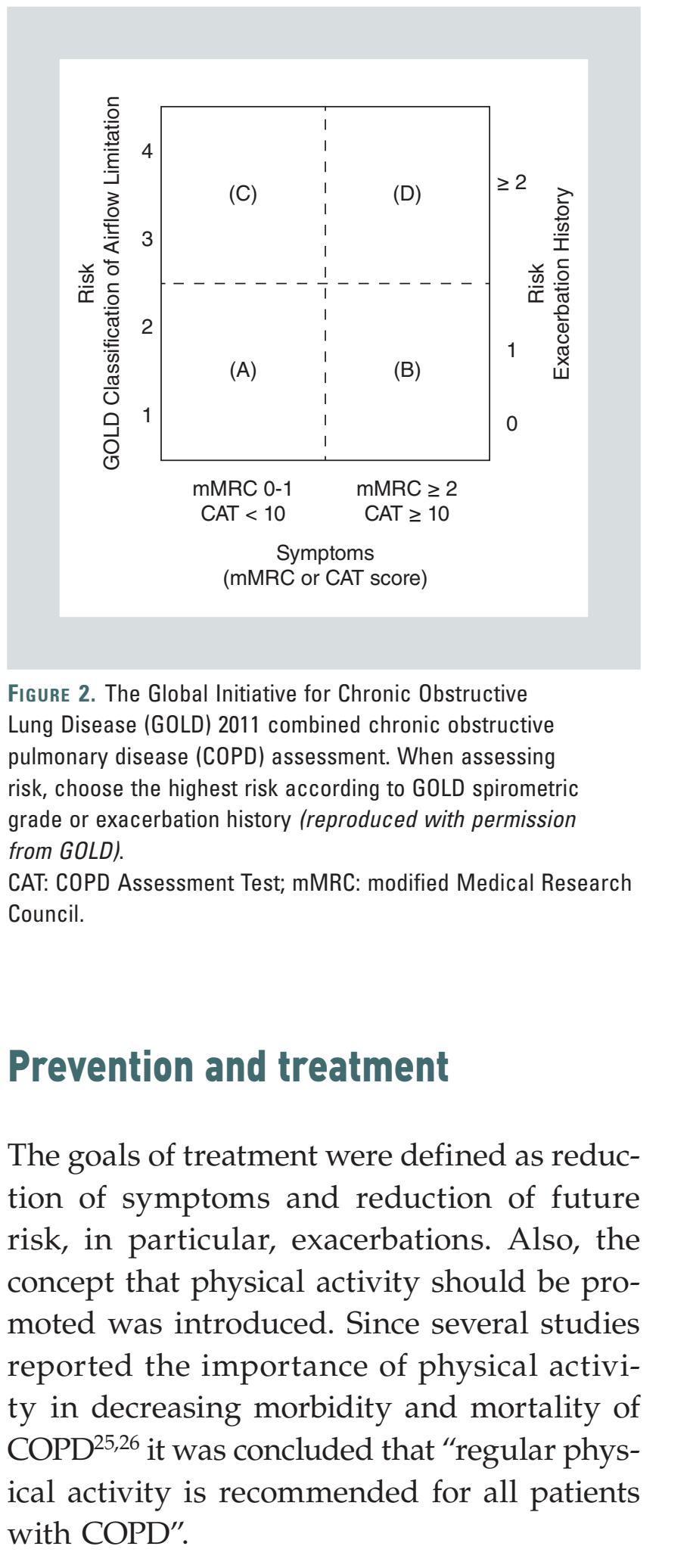

Recommendations for pharmacological treatment were restricted to initiation of treatment. They were divided into "recommended first 
choice", "alternative choice recommendations" and "other possible treatments". Under "recommended first choice" bronchodilators alone or in combination were suggested for all groups A to D, whereas ICS should be restricted to the groups with high exacerbation risk (C and D).

\section{Comorbidities}

Comorbitidities are frequent in patients with COPD comorbidities and may have a major impact on morbidity and mortality ${ }^{27-29}$. Therefore, an entire chapter was devoted to this topic. The most relevant statement was that "in general, the presence of comorbidities should not alter COPD treatment and comorbidities should be treated as if the patient did not have COPD". This is in particular valid for cardiovascular diseases, e.g. the use of $\beta$-blockers is encouraged in patients that have a cardiovascular indication for these agents ${ }^{30}$.

Shortly after the publication of the GOLD 2011 Executive Summary, several questions were raised:

- Do group A and (particularly) group C exist? The frequency of groups A to $\mathrm{D}$ depends on the population studied. In the general population, the most prevalent group is $\mathrm{A}$, whereas in patients recruited from secondary and tertiary care, it is D. The prevalence of group B is around $20 \%$ and group C is the least prevalent, but this is the one that is highly variable ${ }^{31-33}$.

- Does the new system better predict survival than the old one? Soriano et al. ${ }^{34}$ compared the mortality prediction using GOLD
2007 and GOLD 2011. They concluded that neither GOLD COPD assessment systems had sufficient discriminatory power to be used clinically to predict mortality at the individual level. Lange et al. ${ }^{35}$ evaluated two similar populations in Copenhagen using the GOLD 2007 and the GOLD 2011 assessment system. They found that with the old system the survival decreased from GOLD 1 to 4, whereas with GOLD 2011 survival was worse in group B than in group $C$. The reason for that phenomenon was a significant mortality increase attributable to the cardiovascular system and cancer in group B individuals. It is important to realize that the new system was never meant to improve the prediction of survival, but to facilitate an informed decision regarding the appropriate use of treatments.

- Are the suggested thresholds for CAT and mMRC comparable? One analysis concluded that cut-points of $\mathrm{mMRC} \geq 1$ and CAT $\geq 10$ are approximately equivalent in determining low-symptom patients ${ }^{36}$. Nevertheless, the GOLD Scientific Committee believes that it is not useful to compare thresholds of a one-dimensional scale that evaluates dyspnoea only (mMRC) with a multidimensional quality of life questionnaire (CAT).

\section{GOLD 2017}

\section{Definition}

In the revised version ${ }^{37-40}$, the presence of symptoms is emphasized. By doing so, it is acknowledged that the finding of a fixed airflow limitation without corresponding 
symptoms does not necessarily mean that COPD is present (assuming that other diseases with airflow limitation have been excluded). Undoubtedly, symptoms may be underreported. Therefore, in such a case, a thorough evaluation is mandatory. Mentioning "symptoms" in the definition is also meant to underline the standpoint that early case finding, but not screening of asymptomatic individuals is propagated by GOLD, as there is no evidence that this approach may be useful ${ }^{41}$.

Symptoms without the detection of a relevant airflow limitation do not qualify for the diagnosis COPD either. Two studies ${ }^{42,43}$ suggest that patients without evidence of airflow obstruction may have signs of structural lung disease on chest imaging, report exacerbations of respiratory symptoms, and are in part treated with respiratory medications on a chronic basis. Nevertheless, it is currently unclear if these patients have acute or chronic bronchitis, asthma, or an earlier presentation of what will become COPD. Furthermore, the new definition states that patients with COPD may have "airway and/or alveolar abnormalities" to emphasize the importance of emphysema. The GOLD Scientific Committee believes that one of the important research topics for the future is to delineate if a patient has predominately a disease of the airways or emphysema or both, and if this plays a role regarding the choice of treatment(s).

\section{Risk factors}

The importance of abnormal lung development for the development and the natural course of COPD is highlighted. This was driven by two recent publications: Lange et $\mathrm{al}^{44}$ analysed the lung function trajectories of three independent cohorts (Framingham Offspring Cohort, Copenhagen City Heart Study, Lovelace Smokers Cohort) over 22 years. At baseline (mean age " 40 years) the individuals were stratified by $\mathrm{FEV}_{1} \geq 80$ versus $<80 \%$ predicted and the diagnosis of COPD yes versus no. The major finding was that about half of the individuals that later developed COPD, at the age of 20 already had a significantly reduced $\mathrm{FEV}_{1}$ and presented a loss of lung function over time, showing another dynamic than the individuals that had normal $\mathrm{FEV}_{1}$ in early adulthood.

McGeachie et al..$^{45}$ evaluated patterns of lung function growth and decline in children with mild-to-moderate asthma $(n=684$, age 5-12 years) from the Childhood Asthma Management Program (CAMP) and followed them with annual spirometry in the 3rd decade of life. They identified four different patterns: normal growth, early decline, reduced growth, and, reduced growth and early decline.

Thus, based on these findings, there are not only the classical lung function trajectories that may lead to COPD as described by Fletcher and Peto $^{46}$, but at least two others with either an airflow limitation originating in early life that may be caused by e.g. childhood infections, or a loss of lung function by severe childhood asthma ${ }^{47}$. This in turn means that there is not one natural history but at least three natural histories of COPD, and therefore, by analysing change of $\mathrm{FEV}_{1}$ over time in a patient with symptomatic COPD, we may be misleading. Besides, we do not know how this impacts on the efficacy of medications. 

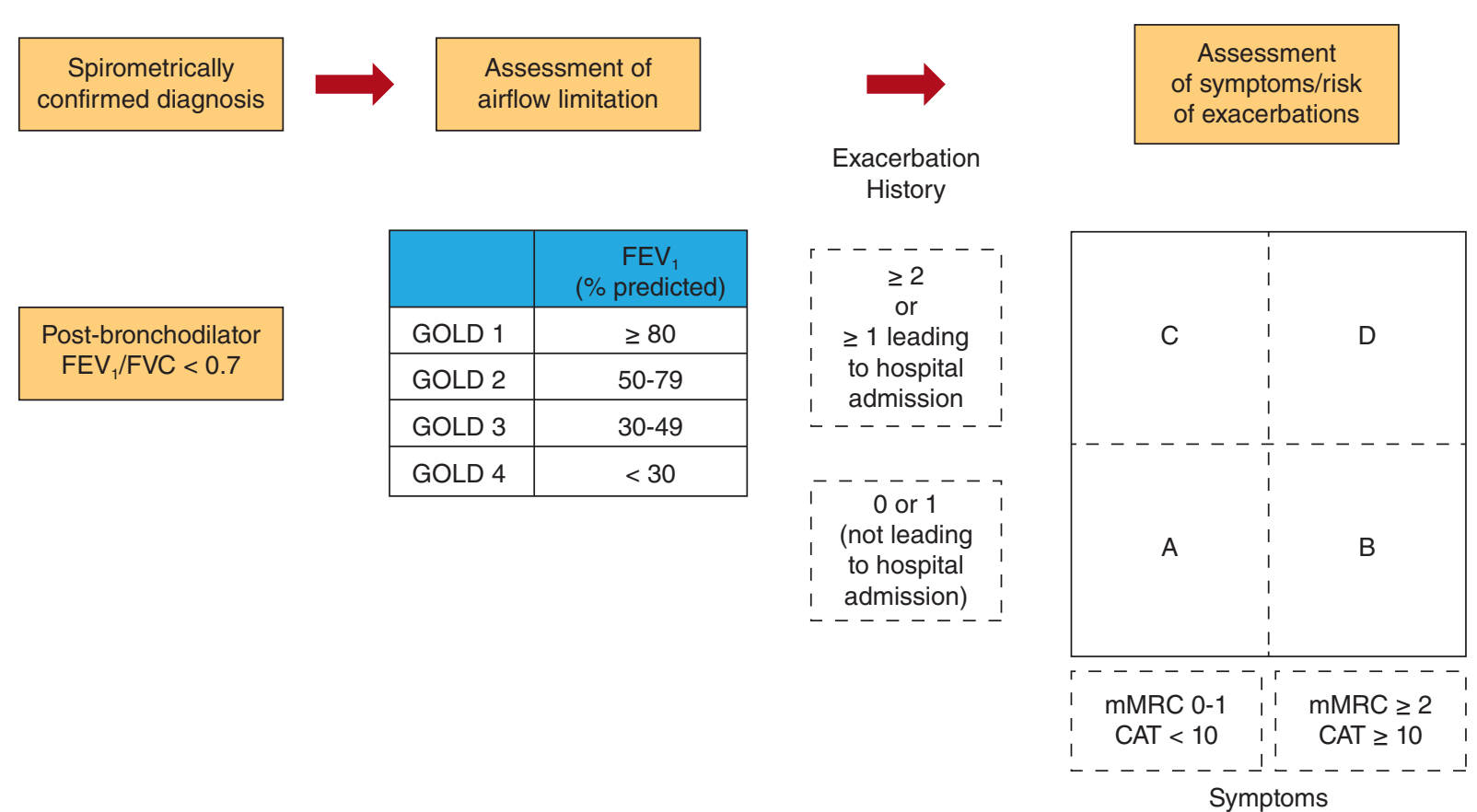

Figure 3. Global Initiative for Chronic Obstructive Lung Disease (GOLD) 2017. The refined ABCD assessment tool (reproduced with permission from GOLD).

CAT: chronic obstructive pulmonary disease (COPD) Assessment Test; FEV $_{1}$ : forced expiratory volume in one second; FVC: forced vital capacity; mMRC: modified Medical Research Council.

Therefore, the discussion is valid if a spirometry should be performed in each individual in early adulthood.

\section{Diagnosis and assessment}

For several reasons, the $A B C D$ system was refined. The most important one was that the two y-axes seem to differ in their predictive power regarding the risk of exacerbations (Fig. 3). The exacerbation history seems to be more relevant than the level of airflow limitation for the individual patient's risk to develop an exacerbation ${ }^{32}$. The spirometric evaluation is separated from the analysis of the symptom load and the exacerbation history (Fig. 3), and the pharmacological treatment is based only on the latter. Spirometry is still of high importance - not only for diagnosis, but also for follow-up, particularly to facilitate decisions regarding non-pharmacological treatments and to identify rapid decliners.

The exceptions from the rule that pharmacological treatment is based on patient-reported outcomes are patients that have a major degree of airflow limitation with minor symptoms (e.g. $\mathrm{FEV}_{1} 30 \%$ predicted, CAT 8). These patients warrant a thorough work-up with exercise test(s) and potentially more sophisticated lung function testing and imaging to define the impact of the disease and the appropriate treatment. 


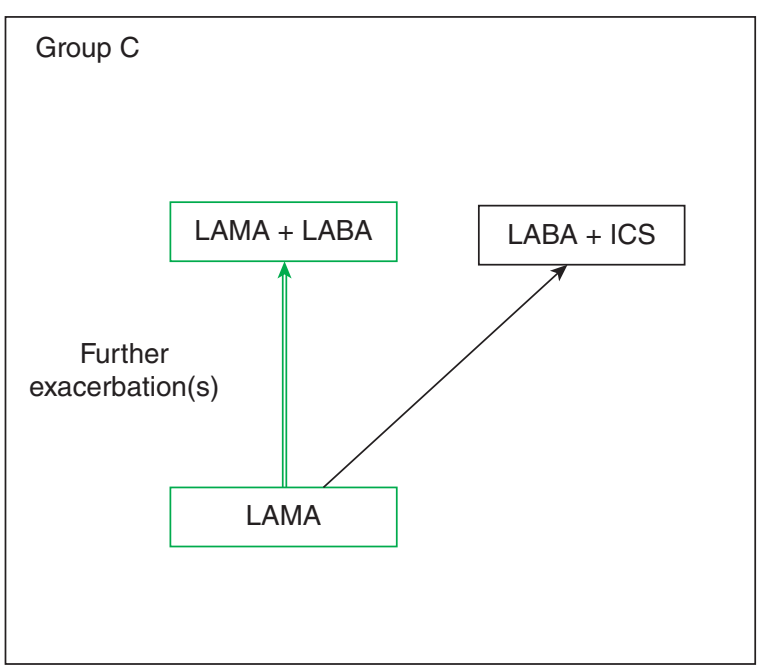

Group A

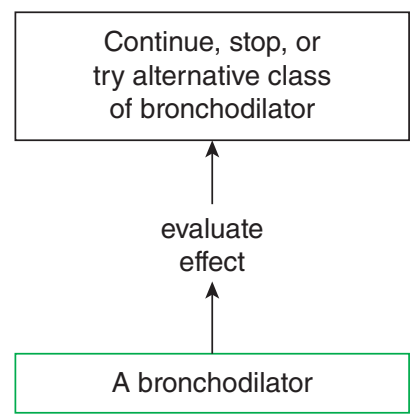

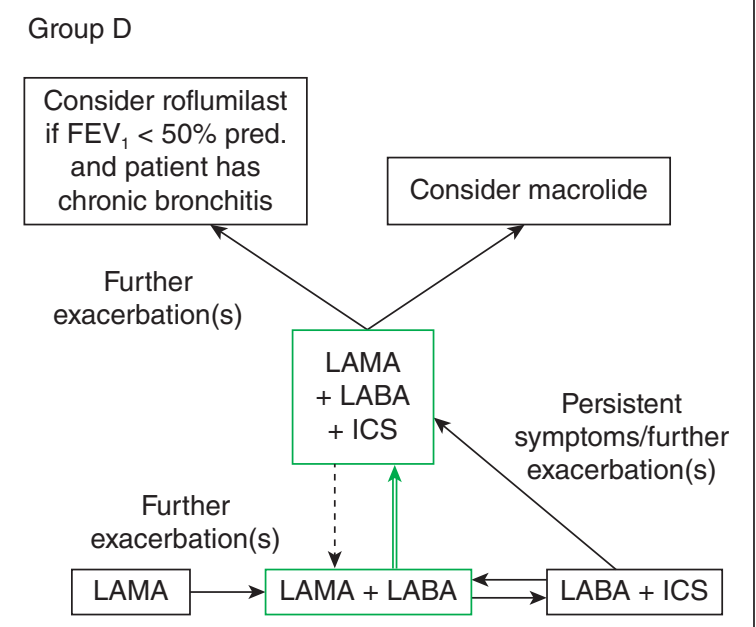

Group B

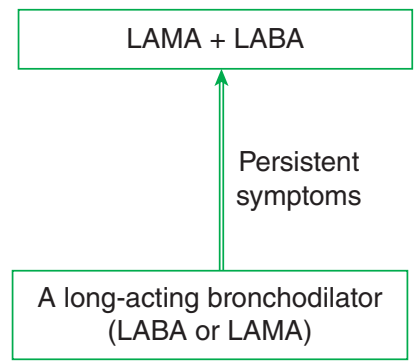

FIgURE 4. Global Initiative for Chronic Obstructive Lung Disease (GOLD) 2017. Pharmacologic treatment algorithms by GOLD grade. Green boxes and arrows indicate preferred treatment pathways (reproduced with permission from GOLD).

$\mathrm{FEV}_{1}$ : forced expiratory volume in one second. ICS: inhaled corticosteroid; LABA: long-acting $\beta$-agonist; LAMA: long-acting muscarinic antagonist.

This novel assessment concept will shift many patients that were (based on lung function) classified as C and D to A and B with consequences regarding the suggested pharmacological management (see below).

\section{Prevention and treatment}

In order to tailor the medication to the individual patient's needs, algorithms are mandatory. Therefore, it was decided to: a) make 
recommendations for each of the groups $A$ to $\mathrm{D}$ separately, and $\mathrm{b}$ ) to include escalation and de-escalation (for ICS) strategies (Fig. 4). Withdrawal of ICS has been studied in several trials with equivocal results ${ }^{48-52}$. In contrast, escalation has not been systematically studied so far. Therefore, the presented algorithms cannot be evidence-based as yet.

The discussion of non-pharmacological treatments of stable disease has been expanded. For the first time, recommendations for end-of-life, palliative and hospice care have been added: they range from measures to relieve breathlessness (e.g. opiates, neuromuscular electrical stimulation (NMES), oxygen, fans), to ways to improve body composition (nutritional supplementation) and reduce fatigue (e.g. selfmanagement education, pulmonary rehabilitation, nutritional support and mind-body interventions). The role of long-term non-invasive ventilation is discussed and the differential indications for the available surgical and interventional therapies in advanced COPD are described.

\section{Comorbidities}

The section has been extended. The problem remains that we know little about: a) the interactions of the lung disease and other organs, in particular the cardiovascular system, and b) the impact of lung medications on other organs and vice versa. Besides, it should be acknowledged that, based on current knowledge, COPD treatments do not modify the course of the disease whereas drugs that are used for common comorbidities (e.g. hypertension, heart failure) do.

\section{Dissemination}

Having in mind that the best document in the world may have only little impact if not disseminated optimally, the GOLD Executive Summary was published in four journals simultaneously in order to cover most of the globe and thereby to achieve the highest possible impact: the American Journal of Respiratory and Critical Care Medicine, the European Respiratory Journal, Respirology and (in Spanish) Archivos de Broncopneumología.

\section{CHALLENGES FOR THE FUTURE}

Recently, an official ATS/ERS statement on research questions in COPD has been published $^{53}$. It deals with many issues that may impact on future GOLD documents. Besides, the fact that in developing countries more and more non-communicable diseases such as COPD play a major role needs to be taken into account. We believe that among others the following issues/questions should be addressed for the next version(s):

\section{Definition, diagnosis and assessment}

What is the best way to define COPD spirometrically? There has been extensive discussion on the use of fixed ratio versus lower limit of normal. Now, a new approach from the Global Lung Initiative (GLI) is to use GLI equations with $z$ scores that were calculated for $\mathrm{FEV}^{1}$, FVC, and FEV1/FVC. It is important that these findings are reproduced in other 
cohorts $^{54,55}$. How can we improve on the detection and quantification of symptoms ${ }^{56}$ ? Are there better methods to identify COPD than spirometry? If so, will it be feasible to use them on a broad scale and not only in developed countries? What will be role of imaging? In this context, is it worth differentiating between dominant airways disease versus emphysema?

\section{Risk factors}

Are there differences between COPD caused by biomass exposure versus smoking that may impact treatment? How do we deal with the issue that reduced lung growth may change the natural course of the disease? What is the role of sex for the development and presentation of the disease? What is the impact of age?

\section{Prevention and treatment}

- General. To what extent is it feasible to implement elements of precision medicine ("treatable traits" ${ }^{\text {"57) }}$ ) to inform treatment decisions?

- Pharmacological Treatment. What is the role of ICS in COPD? Are there biomarkers (eosinophils in peripheral blood and/or others) that may enable us to identify patients that may benefit? What is the role of triple inhaled treatment - LABA-longacting muscarinic antagonist (LAMA)-ICS? Is there additional benefit when an ICS is added to LABA/LAMA?
- Non-pharmacological treatment. How can we improve physical activity? How can rehabilitation be offered to more patients?

- Exacerbations. The current definition is arbitrary and non-specific. Are there biomarkers that allow a more specific definition and, more than that, reveal the cause of the event - viruses, bacteria or others? The treatments that we currently use are not satisfactory. In particular, patients that need to be hospitalized may leave the hospital after one week in a worse condition than at the beginning of the stay as a consequence of being immobilized. Are there strategies to improve body composition even during a hospitalized exacerbation?

\section{Comorbidities}

More information on the interactions between COPD and other diseases, in particular the mechanisms involved, is needed. How do drugs that are used for the lung disease impact on other organs, in particular the cardiovascular system and vice versa? What is the role of systemic inflammation and if it is relevant what can do about it?

\section{Dissemination}

The document has to be adapted to specific audiences: specialists versus general practitioners, clinicians versus researchers, developing versus developed countries. What is the best way to move the document into the digital world? An interactive application for mobile phones is currently under development. 
The implementation of the GOLD document into hospital information systems is under evaluation.

The GOLD Committee would like to start a discussion with other stakeholders (scientific societies, industry, payers, patient support groups) on what the best study designs may be to bring the field forward. This includes the search for biomarkers and novel patientreported outcomes. Regarding knowledge transfer besides moving deeper into the digital world, it will be essential to address the needs of developing countries. This may lead to various versions of the document that have a specific target audience.

\section{ACKNOWLEDGEMENTS}

We thank Roberto Rodriguez-Roisin for carefully reviewing the manuscript.

\section{CONFLICT OF INTEREST}

Dr. Claus Vogelmeier reports personal fees from Almirall, personal fees from AstraZeneca, personal fees from Boehringer Ingelheim, personal fees from Chiesi, grants and personal fees from GlaxoSmithKline, grants and personal fees from Grifols, personal fees from Mundipharma, personal fees from Novartis, personal fees from Takeda, personal fees from Cipla, personal fees from Berlin Chemie/Menarini, personal fees from CSL Behring, personal fees from Teva, outside the submitted work.

Dr. Fernando Martinez reports personal fees from Continuing Education, personal fees from Forest Laboratories, other from Janssen, personal fees from GlaxoSmithKline, personal fees from Nycomed/Takeda, personal fees from AstraZeneca, personal fees from Boehringer Ingelheim, personal fees from Bellerophon (formerly Ikaria), personal fees from Genentech, personal fees from Novartis, personal fees from Pearl, personal fees from Roche, personal fees from Sunovion, personal fees from Theravance, personal fees from CME Incite, personal fees from Annenberg Center for Health Sciences at Eisenhower, personal fees from Integritas, personal fees from InThought, personal fees from National Association for Continuing Education, personal fees from Paradigm Medical Communications, LLC, personal fees from PeerVoice, personal fees from UpToDate, personal fees from Haymarket Communications, personal fees from Western Society of Allergy and Immunology, from Proterixbio (formerly Bioscale), personal fees from Unity Biotechnology, personal fees from ConCert Pharmaceuticals, personal fees from Lucid, personal fees from Methodist Hospital, personal fees from Columbia University, personal fees from Prime Healthcare Ltd, personal fees from WebMD, personal fees from PeerView Network, personal fees from California Society of Allergy and Immunology, personal fees from Chiesi, personal fees from Puerto Rico Thoracic Society, outside the submitted work.

Dr. Gerard Criner reports that the grants or personal fees had no bearing on the work that is presented in the body of the work of the manuscript.

\section{REFERENCES}

\footnotetext{
1. Terminology, Definitions, and Classification of Chronic Pulmonary Emphysema and Related Conditions: A Report of the Conclusions of a Ciba Guest Symposium Thorax. 1959;14:286-299.
} 
2. Mitchell RS, Ryan SF, Petty TL et al. Significance of morphologic chronic hyperplastic bronchitis. Am Rev Respir Dis. 1966;93:720-9.

3. Filley GF. Emphysema and chronic bronchitis: clinical manifestations and their physiologic significance. Med Cin North Am. 1967;51:283-92.

4. Filley GF, Dart GA, Mitchell RS. Emphysema and chronic bronchitis: clinical manifestations and their physiological significance Aspen. Emphysema Conf. 1968;9:339-49.

5. Global Initiative for Chronic Obstructive Lung Disease (GOLD) 20th Anniversary: a brief history of time. Rodriguez-Roisin R, Rabe KF, Vestbo J, Vogelmeier C, Agustí A, on behalf of all previous and current members of the Science Committee and the Board of Directors of GOLD (goldcopd.org/ committees/). Eur Respir J. 2017;0:1700671 (In Press).

6. Pauwels RA, Buist AS, Ma P et al. Global strategy for the diagnosis, management, and prevention of chronic obstructive pulmonary disease: National Heart, Lung, and Blood Institute and World Health Organization Global Initiative for Chronic Obstructive Lung Disease (GOLD): executive summary. Respir Care. 2001;46:798-825.

7. Standards for the diagnosis and care of patients with chronic obstructive pulmonary disease (COPD) and asthma. This official statement of the American Thoracic Society was adopted by the ATS Board of Directors, November 1986. Am Rev Respir Dis. 1987;136:225-44.

8. British Thoracic Society: guidelines for the management of chronic obstructive pulmonary disease. Thorax. 1997;52:S1-S28.

9. Siafakas NM, Vermeire P, Pride NB et al. ERS consensus statement: optimal assessment and management of chronic obstructive pulmonary disease. Eur Respir J. 1995;8:1398-420.

10. Pauwels RA, Lofdahl CG, Laitinen LA et al. Long-term treatment with inhaled budesonide in persons with mild chronic obstructive pulmonary disease who continue smoking. European Respiratory Society Study on Chronic Obstructive Pulmonary Disease. N Engl J Med. 1999;340: 1948-53.

11. Vestbo J, Sorensen T, Lange P et al. Long-term effect of inhaled budesonide in mild and moderate chronic obstructive pulmonary disease: a randomised controlled trial. Lancet. 1999;353:1819-23.

12. Burge PS, Calverley PM, Jones PW et al. Randomised, double blind, placebo controlled study of fluticasone propionate in patients with moderate to severe chronic obstructive pulmonary disease: the ISOLDE trial. BMJ. 2000; 320:1297-303.

13. The Lung Health Study Research Group. Effect of inhaled triamcinolone on the decline in pulmonary function in chronic obstructive pulmonary disease: N Engl J Med. 2000;343:1902-9.

14. Rabe KF, Hurd S, Anzueto A et al. Global strategy for the diagnosis, management, and prevention of chronic obstructive pulmonary disease: GOLD executive summary. Am J Respir Crit Care Med. 2007;176:532-5.

15. Vestbo J, Lange P. Can GOLD Stage 0 provide information of prognostic value in chronic obstructive pulmonary disease? Am J Respir Crit Care Med. 2002;166:329-32.

16. Jones PW, Willits LR, Burge PS et al. Disease severity and the effect of fluticasone propionate on chronic obstructive pulmonary disease exacerbations. Eur Respir J. 2003;21:68-73.

17. Mahler DA, Wire P, Horstman D et al. Effectiveness of fluticasone propionate and salmeterol combination delivered via the Diskus device in the treatment of chronic obstructive pulmonary disease. Am J Respir Crit Care Med. 2002;166:1084-91.

18. Calverley P, Pauwels R, Vestbo J et al. Combined salmeterol and fluticasone in the treatment of chronic obstructive pulmonary disease: a randomised controlled trial. Lancet. 2003;361:449-56.

19. SzafranskiW, Cukier A, Ramirez A et al. Efficacy and safety of budesonide/ formoterol in the management of chronic obstructive pulmonary disease. Eur Respir J. 2003;21:74-81.

20. Vestbo J, Hurd SS, Agustí AG et al. Global strategy for the diagnosis, management, and prevention of chronic obstructive pulmonary disease: GOLD executive summary. Am J Respir Crit Care Med. 2013;187:347-65.
21. Jones P, Harding G, Wiklund I et al. Improving the process and outcome of care in COPD: development of a standardised assessment tool. Prim Care Respir J. 2009;18:208-15.

22. Jones PW, Harding G, Berry P et al. Development and first validation of the COPD Assessment Test. Eur Respir J. 2009;34:648-54.

23. Bestall JC, Paul EA, Garrod R et al. Usefulness of the Medical Research Council (MRC) dyspnoea scale as a measure of disability in patients with chronic obstructive pulmonary disease. Thorax. 1999;54:581-6.

24. Hurst JR, Vestbo J, Anzueto A et al. Susceptibility to exacerbation in chronic obstructive pulmonary disease. N Engl J Med. 2010;363:1128-38.

25. Garcia-Aymerich J, Lange $\mathrm{P}$, Benet $\mathrm{M}$ et al. Regular physical activity reduces hospital admission and mortality in chronic obstructive pulmonary disease: a population based cohort study. Thorax. 2006;61:772-8.

26. Waschki B, Kirsten A, Holz O et al. Physical activity is the strongest predictor of all-cause mortality in patients with COPD: a prospective cohor study. Chest. 2011;140:331-42.

27. Mannino DM, Thorn D, Swensen A et al. Prevalence and outcomes of diabetes, hypertension and cardiovascular disease in COPD. Eur Respir J. 2008;32:962-9.

28. Sin DD, Anthonisen NR, Soriano JB et al. Mortality in COPD: role of comorbidities. Eur Respir J. 2006;28:1245-57.

29. Soriano JB, Visick GT, Muellerova $\mathrm{H}$ et al. Patterns of comorbidities in newly diagnosed COPD and asthma in primary care. Chest. 2005;128:2099-107.

30. Salpeter S, Ormiston T, Salpeter E. Cardioselective beta-blockers for chronic obstructive pulmonary disease. Cochrane Database Syst Rev. 2005;CD003566.

31. Agusti A, Hurd S, Jones P et al. FAQs about the GOLD 2011 assessment proposal of COPD: a comparative analysis of four different cohorts. Eur Respir J. 2013;42:1391-401.

32. Haughney J, Gruffydd-Jones K, Roberts J et al. The distribution of COPD in UK general practice using the new GOLD classification. Eur Respir J. 2014;43:993-1002.

33. Singh D, Ravi A. Management of chronic obstructive pulmonary disease a personalized interpretation of the Global Initiative for Chronic Obstructive Lung Disease (GOLD) - ABCD recommendations. BRN Rev. 2016;2 27-39.

34. Soriano JB, Lamprecht B, Ram;rez AS et al. Mortality prediction in chronic obstructive pulmonary disease comparing the GOLD 2007 and 2011 staging systems: a pooled analysis of individual patient data. Lancet Respir Med. 2015;3:443-50.

35. Lange P, Marott JL, Vestbo J et al. Prediction of the clinical course of chronic obstructive pulmonary disease, using the new GOLD classification: a study of the general population. Am J Respir Crit Care Med. 2012; 186:975-81.

36. Jones PW, Adamek L, Nadeau G et al. Comparisons of health status scores with MRC grades in COPD: implications for the GOLD 2011 classification. Eur Respir J. 2013;42:647-54.

37. Vogelmeier CF, Criner GJ, Martinez FJ et al. Global Strategy for the Diagnosis, Management, and Prevention of Chronic Obstructive Lung Disease 2017 Report. GOLD Executive Summary. Am J Respir Crit Care Med 2017;195:557-82.

38. Vogelmeier CF, Criner GJ, Martinez FJ et al. Global Strategy for the Diag nosis, Management, and Prevention of Chronic Obstructive Lung Diseas 2017 Report: GOLD Executive Summary. Eur Respir J. 2017;49. pii: 1700214 doi: 10.1183/13993003.00214-2017.

39. Vogelmeier CF, Criner GJ, Martinez FJ et al. Global Strategy for the Diag nosis, Management and Prevention of Chronic Obstructive Lung Disease 2017 Report: GOLD Executive Summary. Respirology. 2017;22:575-601.

40. Vogelmeier CF, Criner GJ, Martínez FJ et al. Global Strategy for the Diagnosis, Management, and Prevention of Chronic Obstructive Lung Disease 2017 Report: GOLD Executive Summary. Arch Bronconeumol. 2017;53:128-49.

41. US Preventive Services Task Force (USPSTF), Siu AL, Bibbins-Domingo K et al. Screening for Chronic Obstructive Pulmonary Disease: US Preventive Services Task Force Recommendation Statement. JAMA. 2016;315:1372-7. 
42. Regan EA, Lynch DA, Curran-Everett D et al. Clinical and Radiologic Disease in Smokers With Normal Spirometry. JAMA Intern Med. 2015;175: 1539-49.

43. Woodruff PG, Barr RG, Bleecker E et al. Clinical Significance of Symptoms in Smokers with Preserved Pulmonary Function. N Engl J Med. 2016;374: 1811-21.

44. Lange P, Celli B, Agustí A et al. Lung-Function Trajectories Leading to Chronic Obstructive Pulmonary Disease. N Engl J Med. 2015;373:111-22.

45. McGeachie MJ, Yates KP, Zhou X et al. Patterns of Growth and Decline in Lung Function in Persistent Childhood Asthma. N Engl J Med. 2016;374: 1842-52.

46. Fletcher C, Peto R. The natural history of chronic airflow obstruction. Br Med J. 1977;1:1645-8

47. Martinez FD. Early-Life Origins of Chronic Obstructive Pulmonary Disease. N Engl J Med. 2016;375:871-8.

48. Nadeem NJ, Taylor SJ, Eldridge SM. Withdrawal of inhaled corticosteroids in individuals with COPD--a systematic review and comment on trial methodology. Respir Res. 2011;12:107.

49. van der Valk P, Monninkhof E, van der Palen J et al. Effect of discontinuation of inhaled corticosteroids in patients with chronic obstructive pulmonary disease: the COPE study. Am J Respir Crit Care Med. 2002;166:1358-63.
50. Wouters EF, Postma DS, Fokkens B et al. Withdrawal of fluticasone propionate from combined salmeterol/fluticasone treatment in patients with COPD causes immediate and sustained disease deterioration: a randomised controlled trial. Thorax. 2005;60:480-7.

51. Kunz LI, Postma DS, Klooster K et al. Relapse in FEV1 Decline After Steroid Withdrawal in COPD. Chest. 2015;148:389-96.

52. Magnussen H, Disse B, Rodriguez-Roisin R et al. Withdrawal of inhaled glucocorticoids and exacerbations of COPD. N Engl J Med. 2014;371:1285-94.

53. Celli BR, Decramer M, Wedzicha JA et al. An official American Thoracic Society/European Respiratory Society statement: research questions in COPD. Eur Respir Rev. 2015;24:159-72.

54. Vaz Fragoso CA, McAvay G, Van Ness PH et al. Phenotype of normal spirometry in an aging population. Am J Respir Crit Care Med. 2015;192:817-25.

55. Vaz Fragoso CA, McAvay G, Van Ness PH et al. Phenotype of Spirometric Impairment in an Aging Population. Am J Respir Crit Care Med. 2016;193. 727-35.

56. Rodriguez-Roisin R, Han MK, Vestbo J et al. Chronic Respiratory Symptoms with Normal Spirometry. A Reliable Clinical Entity? Am J Respir Crit Care Med. 2017;195:17-22.

57. Agusti A, Bel E, Thomas $\mathrm{M}$ et al. Treatable traits: toward precision medicine of chronic airway diseases. Eur Respir J. 2016;47:410-9. 